\title{
Microfluidic Screening to Study Acid Mine
}

\section{Drainage}

Die Yang ${ }^{a}$, Rong Fan ${ }^{b}$, Christopher Greet ${ }^{c}$ and Craig Priest ${ }^{a, d^{*}}$

a Future Industries Institute, University of South Australia, Mawson Lakes, SA 5095, Australia

${ }^{\mathrm{b}}$ CSIRO Mineral Resources, Private Bag 10, Clayton South, VIC, 3169, Australia

${ }^{\mathrm{c}}$ Magotteaux Australia PTY Ltd, 31 Cormack Road, Wingfield SA 5013, Australia.

dUniSA STEM, University of South Australia, Mawson Lakes, SA 5095, Australia.

*Corresponding author email address: Craig.Priest@,unisa.edu.au 


\section{TABLE OF CONTENTS}

Figure S1. Plot of $\log r$ versus $\log m_{H}^{+}$.

Figure S2. Linear regression analysis of rate data for the aqueous oxidation of pyrite by ferric ion at different temperatures.

Figure S3. Arrhenius plot for the oxidation reaction of pyrite at different ferric ion concentrations and temperatures.

Figure S4. Fitted S (2p) XPS spectra of the pyrite samples treated at different conditions. 


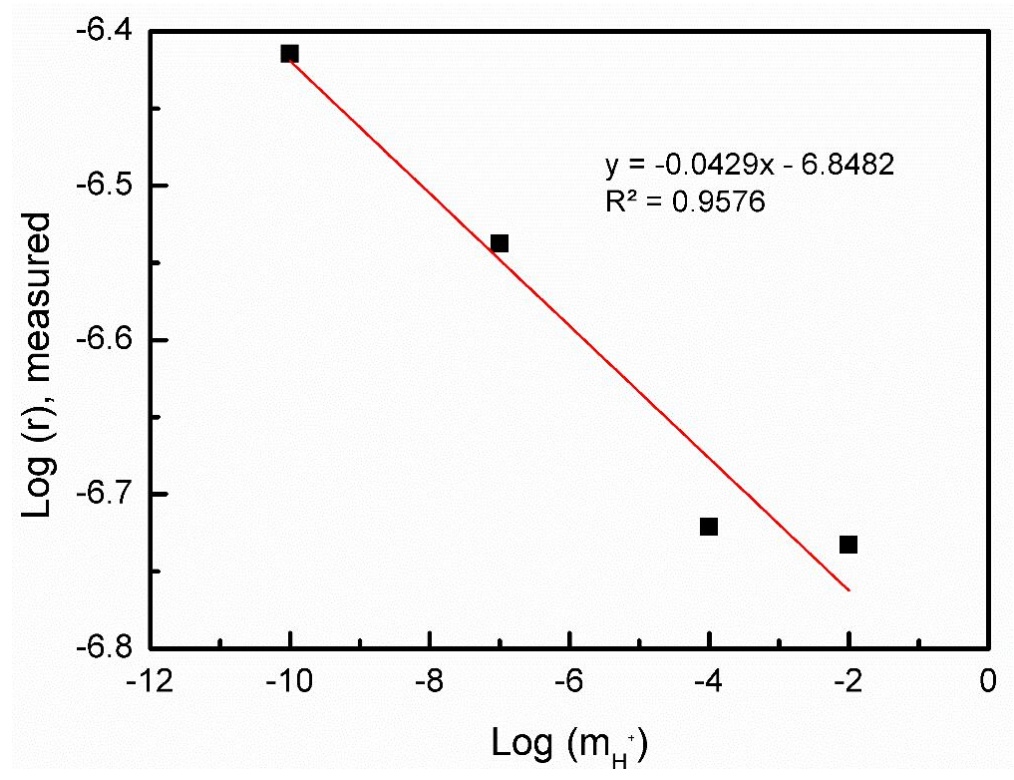

Figure S1. Plot of $\log r\left(r\right.$ is the rate of pyrite dissolution in mol. $\left.\mathrm{m}^{-2} \cdot \mathrm{s}^{-1}\right)$ versus $\log m_{H}^{+}\left(m_{H}^{+}\right.$ is the concentration of $\mathrm{H}^{+}$in fresh aqueous solution in mol. $\mathrm{L}^{-1}$ ). 


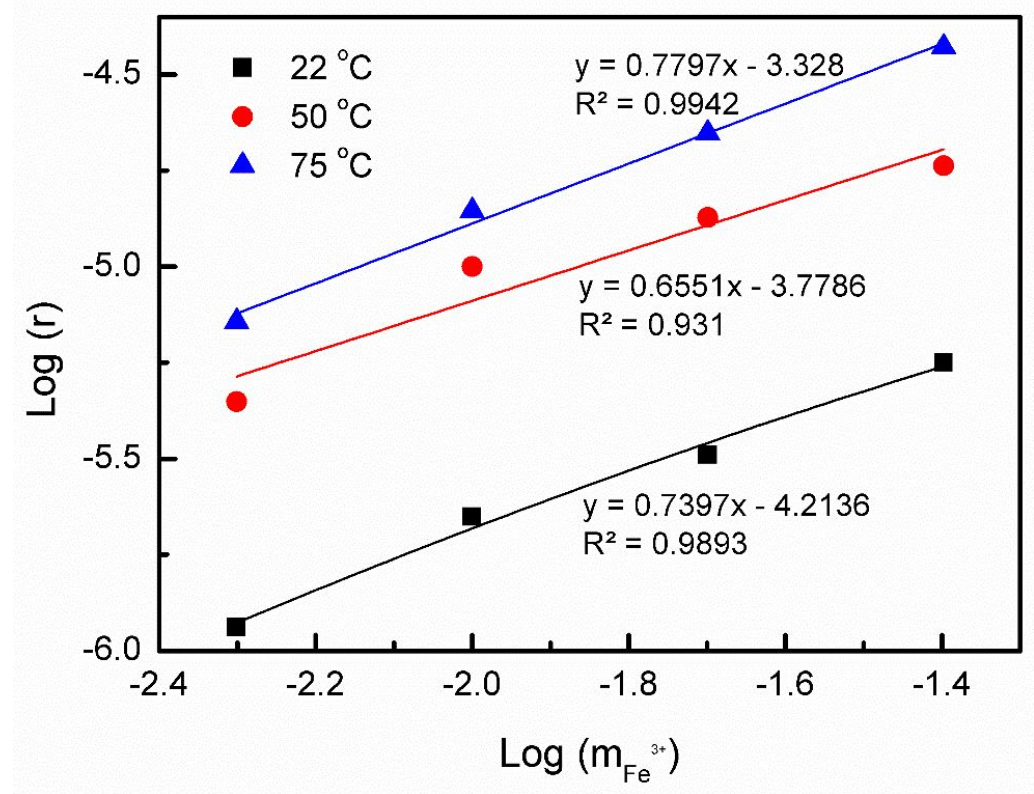

Figure S2. Linear regression analysis of rate data for the aqueous oxidation of pyrite by ferric ion at different temperatures, where $r$ represents the rate of pyrite dissolution in $\mathrm{mol} \cdot \mathrm{m}^{-2} \cdot \mathrm{s}^{-1}$ and $m_{\mathrm{Fe}}^{3+}$ represents the concentration of $\mathrm{Fe}^{3+}$ in fresh aqueous solution in mol.L-1. 


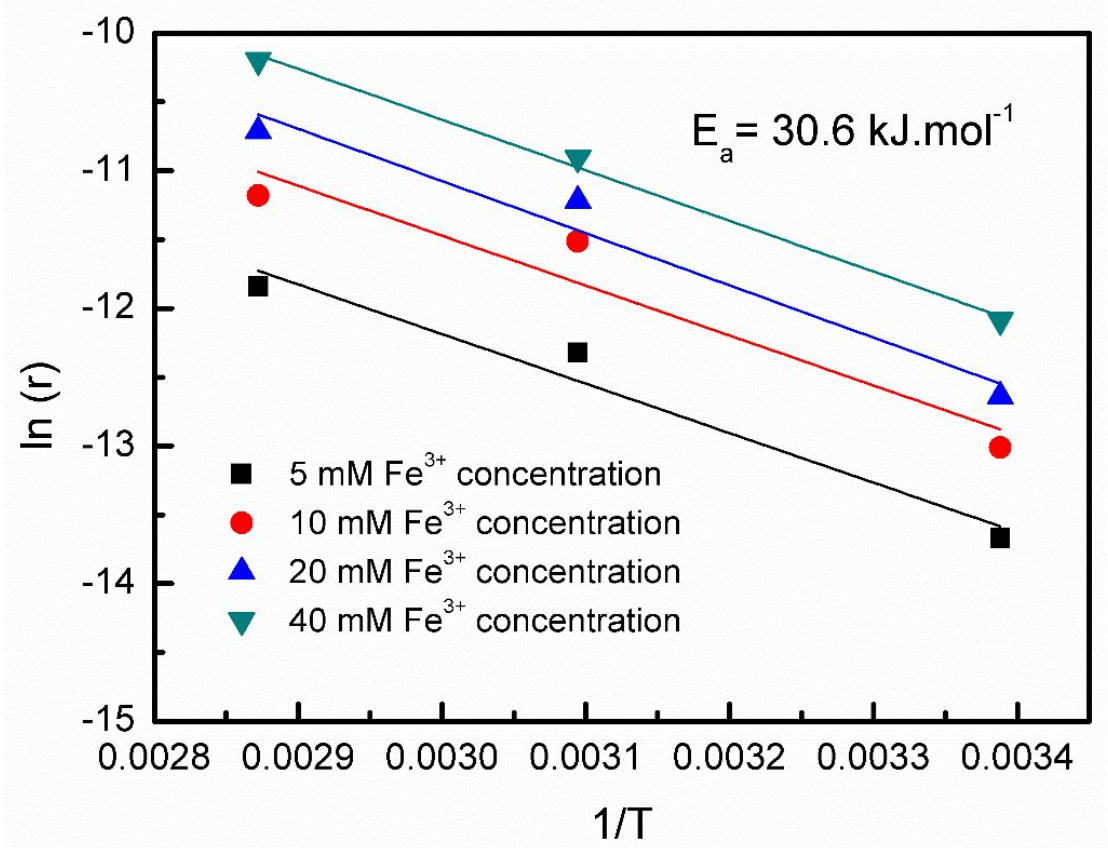

Figure S3. Arrhenius plot for the oxidation reaction of pyrite at different ferric ion concentrations and temperatures $(\mathrm{pH}=2$, ionic strength $0.1 \mathrm{M} \mathrm{KCl})$, where $r$ represents the rate of pyrite dissolution in mol. $\mathrm{m}^{-2} \cdot \mathrm{s}^{-1}$. 

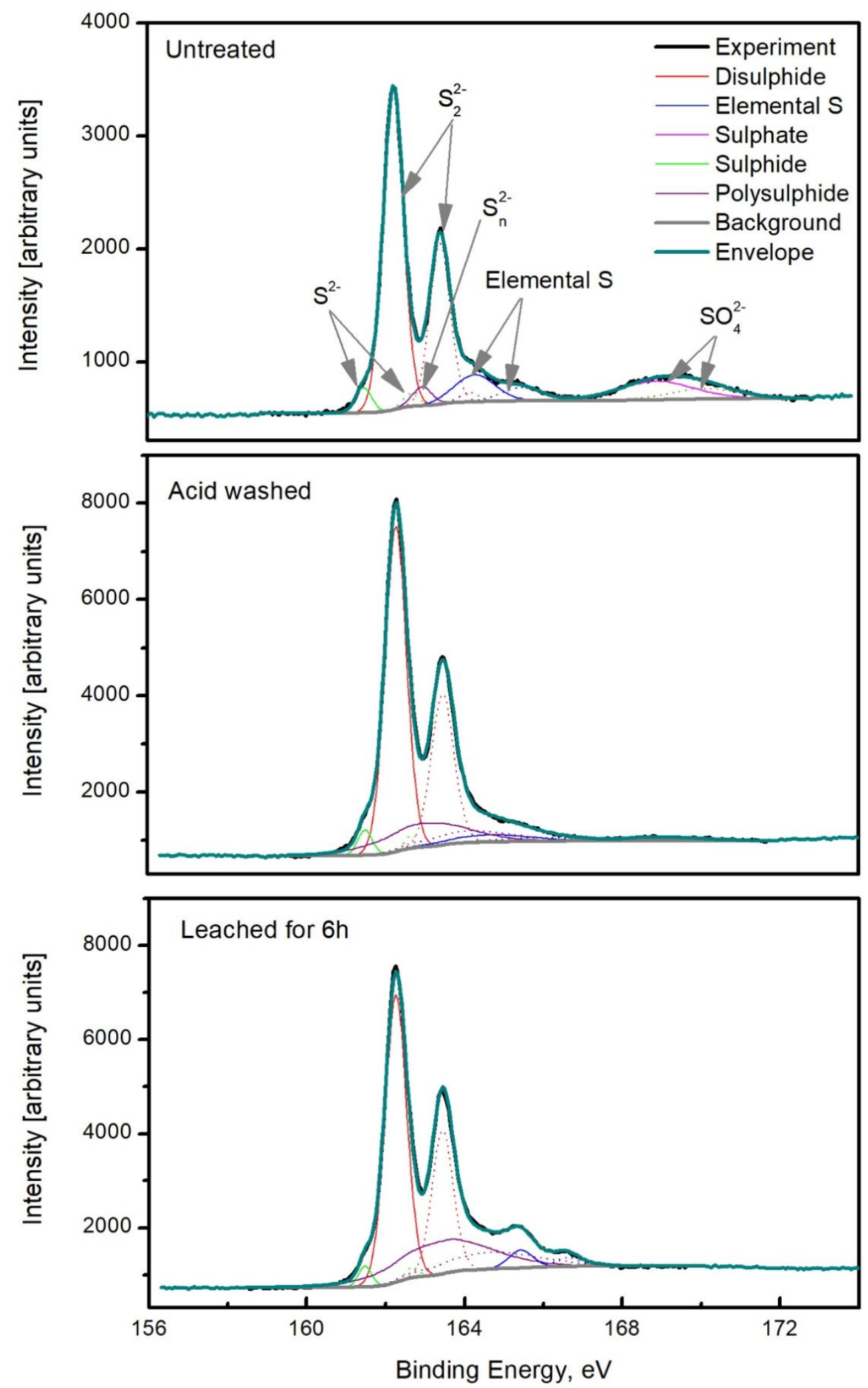

Figure S4. Fitted S (2p) XPS spectra of the pyrite samples treated at different conditions. Note that dotted line showing the doublet peak of each S species of the same color. 